\title{
STRAWBERRY GALLBLADDER: A CASE REPORT
}

Floret Soundrapandian'1, Balaji Durairaj², Alankrith Ramesh Kashyap ${ }^{3}$, Reegan Jose 4

1 Professor, Department of General Surgery, SRM Medical College Hospital \& Research Centre, Chennai.

${ }^{2}$ Assistant Professor, Department of General Surgery, SRM Medical College Hospital \& Research Centre, Chennai.

3 Post Graduate, Department of General Surgery, SRM Medical College Hospital \& Research Centre, Chennai.

${ }^{4}$ Post Graduate, Department of General Surgery, SRM Medical College Hospital \& Research Centre, Chennai.

\begin{abstract}
BACKGROUND

Cholesterolosis is an uncommon surgical condition characterized by abnormal and excessive deposition of cholesterol esters and triglycerides within the macrophages in gallbladder. Cholesterolosis is more common in females around $6^{\text {th }}$ decade and relatively rare in young individuals. Cholesterolosis can occur due to increased uptake of cholesterol from supersaturated bile. Cholesterolosis need not necessarily show high levels of serum cholesterol levels or presence of cholesterol stones. This indicates that it is possible for a patient to develop cholesterolosis even in absence of risk factors presenting as acute cholecystitis, which warrants further need to understand this rare form of an uncommon disease. We present a young female who had complaints of only right hypochondrial pain first episode, she was diagnosed as cholecystitis clinically. Her ultrasound report showed multiple gallbladder polyps. She underwent elective laparoscopic cholecystectomy and postoperative recovery was uneventful. Her histopathological report revealed cholesterolosis with chronic calcific cholecystitis. Case presented for its occurrence at early age with no risk factor and it needs to be differentiated from gallbladder malignancy and other disorder of gallbladder where management differs.
\end{abstract}

\section{KEYWORDS}

Cholesterolosis, Strawberry Gallbladder, Cholecystitis.

HOW TO CITE THIS ARTICLE: Soundrapandian F, Durairaj B, Kashyap AR, et al. Strawberry gallbladder: a case report. J. Evolution Med. Dent. Sci. 2016;5(24):1313-1314, DOI: 10.14260/jemds/2016/307

\section{INTRODUCTION \\ CASE REPORT}

A 20 yrs. old female was admitted with complaints of intermittent right hypochondrial pain for 1 week. On examination, tenderness in the right hypochondrium was noted. She was afebrile and not icteric. No disturbances in bowel and bladder habits. Vitals recorded were stable. Routine blood investigations (Total Count: 7000 cells/cu.mm; Total Bilirubin: $1 \mathrm{mg} / \mathrm{dL}$; Indirect bilirubin: $0.2 \mathrm{mg} / \mathrm{dL}$; Direct bilirubin: $0.8 \mathrm{mg} / \mathrm{dL}$; Total Protein: $8 \mathrm{~g} / \mathrm{dL}$; Albumin $5 \mathrm{~g} / \mathrm{dL}$ ) and lipid profile (Total Cholesterol: $160 \mathrm{mg} / \mathrm{dL}$; LDL: 90 mg/dL; HDL: $45 \mathrm{mg} / \mathrm{dL}$ ) were within normal limits.

Her Ultrasound Abdomen Revealed

Multiple Gallbladder Polyps; Thickened Gallbladder Wall; No Evidence of Calculi (Figure 1).

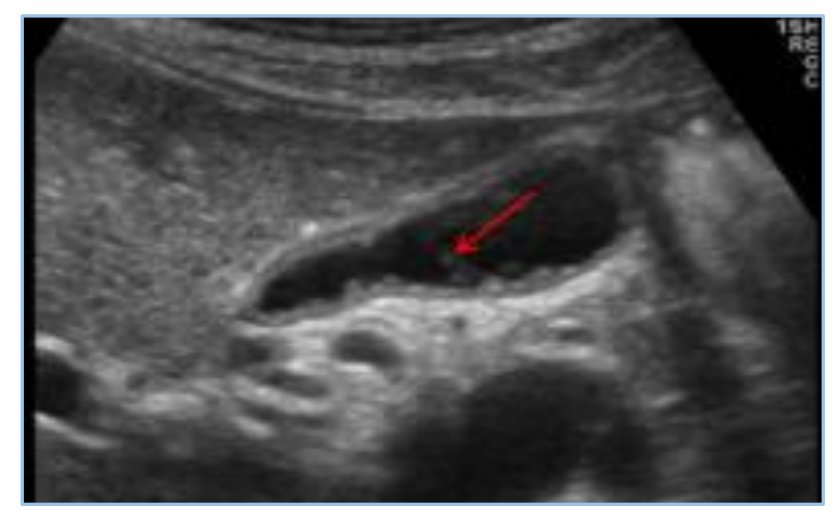

Fig. 1

Patient underwent elective laparoscopic cholecystectomy.

Financial or Other, Competing Interest: None.

Submission 09-02-2016, Peer Review 04-03-2016,

Acceptance 11-03-2016, Published 24-03-2016.

Corresponding Author:

Dr. Alankrith Ramesh Kashyap,

Room 308, PG Medical Gents Hostel,

SRM College Hospital \& Research Centre,

SRM Nagar, Kattankulathur, Chennai-603203,

E-mail: koolchant@gmail.com

DOI: 10.14260/jemds/2016/307

\section{Intraoperative Findings}

Gallbladder was found to be inflamed. Cut section of the specimen showed congested, thickened GB wall with yellowish deposits with multiple concretions free and adherent to mucosa (Figure 2, 3).

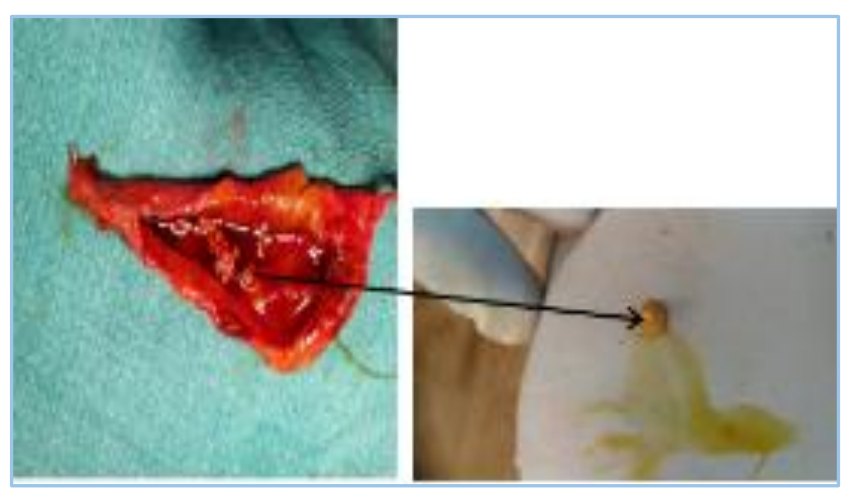

Fig. 2

Fig. 3

\section{Histopathology}

Columnar epithelium with basally placed nucleus showing mucosal prolapse into the muscularis - Chronic Calculous Cholecystitis with Cholesterolosis (Figure 4, 5).

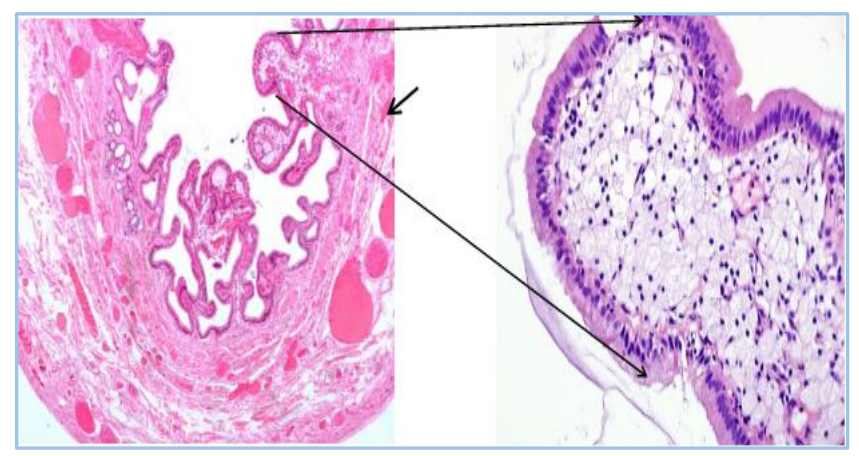

Fig. 4 


\section{DISCUSSION}

The pathogenesis of cholesterolosis is not very clear and remains questionable, though many theories and studies have been documented, thus making it difficult to accurately calculate the incidence.1,2 One study involving 1319 autopsy cases showed an incidence of $12.5 \% .^{3}$ Cholesterol polyps and cholesterolosis may infrequently occur together. ${ }^{4}$ An incidental finding related to fatty steatosis-lipid laden macrophages in lamina propria of gallbladder epithelium is cholesterolosis. ${ }^{2,5}$ In literature the incidence varies from $2.7 \%$ to $28.6 \%{ }^{6}$ Though the pathogenesis is still an enigma and many mechanisms in literature for the same have been proposed; cholesterolosis can occur due to increased uptake of cholesterol from supersaturated bile.2,5 Excessive stimulation of cholesterol acyltransferase by biliary cholesterol can lead to increased deposition of esterified cholesterol in the gallbladder mucosa. ${ }^{6}$ Venous and lymphatic stasis disturbing the secretive and absorptive functions of gallbladder epithelium together with muscularis (Lamina) propria dysfunction: $G$ proteins are not activated when cholecystokinin binds to receptors on smooth muscle cells in cholelithiasis also play a role. 6

Though cholesterolosis may be associated with cholesterol stones and high serum cholesterol levels, there are situations where they may not be so.1,6,7 Cholesterolosis can be considered as a rare manifestation of persistently raised serum cholesterol levels more common in obese individuals and unhealthy lifestyle, such as alcohol intake and smoking. 2,6,8 Macroscopically lipid deposits appear as yellow flecks against dark background, thus earning the moniker 'Strawberry Gallbladder.2' The diffuse variety of cholesterolosis appears as a carpet of fine yellow papules over mucosa surface, whereas polypoid variety shows single or multiple polyps. ${ }^{4}$ Patient presentation can vary from asymptomatic (Most often) to pain in right hypochondrium similar to or superadded with chronic cholecystitis, pain occurring due to hypercontraction of gallbladder or free floating debris causing intermittent biliary colic.3,4 Ultrasound may show gallbladder polyps with or without gallstones and biliary sludge.4 Laparoscopic cholecystectomy is safe with add-on benefits of early discharge, return to normal activity and good cosmetic results. ${ }^{6}$

\section{CONCLUSION}

Cholesterolosis though cited in many archives remains a benign ambiguous entity due to its inconclusive epidemiology, controversial association with variety of diseases, viz. hypercholesterolaemia, alcohol and smoking, cholelithiasis, cholecystitis and relatively asymptomatic course, but safe and potentially treatable with cholecystectomy.

\section{REFERENCES}

1. Mark Feldman, Lawrence S Friedman, Lawrence J Brandt. Sleisenger and fordtran's gastrointestinal and liver disease: pathophysiology, diagnosis, management. 2015;10:1157.

2. Robert D Odze, John R Goldblum. Odze and goldblum surgical pathology of the GI tract, liver, biliary tract and pancreas. 2014;1010.

3. Richard M Gore, Marc S Levine. Textbook of Gastrointestinal radiology. 2014;1379.

4. Ljubicic N, Zovak M, Doko M, et al. Management of gallbladder polyps: an optimal strategy proposed. Acta clin Croat 2001;40:57-60.

5. Kumar V, Abbas AK, Fausto N Robins, et al. Pathologic basis of disease. Elsevier publication, 2004;7:37, 930.

6. Khairy Gamal A, Guraya Salman Y, Murshid Khalid R. Cholesterolosis. Incidence, correlation with serum cholesterol level and role of laparoscopic cholecysytectomy. Saudi Med J 2004;25(9):1226-8.

7. Méndez-Sánchez N, Tanimoto MA, Cobos E, et al. Cholesterolosis is not associated with high cholesterol levels in patients with and without gallstone disease. J Clin Gastroenterol 1997;25(3):518-21.

8. Sandri L, Colecchia A, Larocca A, et al. Gallbladder cholesterol polyps and cholesterolosis. Minerva Gastroenterol Dietol 2003;49(3):217-24. 